\title{
Knowledge of parents/caregivers about bruxism in children treated at the pediatric dentistry clinic
}

Chirlene Lemos Alves ${ }^{1}$ Daniela Malagoni Fagundes ${ }^{1}$ Priscilla Barbosa Ferreira Soares ${ }^{2}$ Meire Coelho Ferreira ${ }^{1}$

${ }^{1}$ Universidade Ceuma, Dentistry Department - São Luís - Maranhão Brazil.

${ }^{2}$ Universidade Federal de Uberlândia, Department of Periodontics and Implantology - Uberlândia - Minas Gerais - Brazil.

\section{Corresponding author:} Meire Coelho Ferreira E-mail: meirecofe@hotmail.com Received: Month February 25, 2019; Accepted: Month August 20, 2019.

\begin{abstract}
Objective: To evaluate the knowledge on bruxism among parents/caregivers of children treated at the pediatric dentistry clinic. Methods: A cross-sectional study was conducted with 103 parents/ caregivers that filled out a questionnaire based on the criteria of the American Association of Sleep Medicine during the dental care offered to their children. The questionnaire addressed demographic issues of the child and caregiver, issues related to child's sleep characteristics (duration, quality and whether he/she sleeps alone) and questions about bruxism (knowledge of the parafunctional habit, bruxism in the caregiver and the child, search for treatment, causes and consequences of bruxism, and whether the caregivers wanted more information on the subject). Pearson's $\chi 2$ test and Fisher's exact test were performed $(\alpha=5 \%)$. Results: Sixty-seven percent reported knowing what bruxism is and $52.4 \%$ correctly described the parafunctional habit. Regarding the cause, $74.8 \%$ were unable to say and $16.5 \%$ associated the habit to an emotional factor. The prevalence of bruxism was $25.2 \%$ and $16.5 \%$ in the children and caregivers, respectively. Among the caregivers of children with bruxism, only $2.9 \%$ had sought some type of help. Child's sex, child's sleep and the search for help were significantly associated with bruxism $(\phi=0.034,0.013$ and $<0.001$, respectively). Conclusion: The knowledge among caregivers about bruxism is still insufficient, especially with regard to the etiology of the parafunctional habit. The lack of knowledge impedes caregivers from seeking help, and thus contributes to the worsening consequences of bruxism in adulthood.
\end{abstract}

Keywords: Knowledge; Parents; Sleep Bruxism; Pediatric Dentistry. 


\section{INTRODUCTION}

The term bruxism is an adaptation of the expression "la bruxomania" first described in medical literature by Marie Pietkiewicz in 1907'. The word comes from the Greek "brychein", which means clenching, friction or grinding the teeth, and the term "mania", which is defined as compulsion. The current concept of bruxism is defined as activity of the masticatory muscles that can occur during sleep (characterized as rhythmic/phasal or non-rhythmic tonal) or while awake (characterized by repetitive or sustained contact of the teeth and/or the pushing out of the mandible) $)^{2}$.

The undesirable forces stemming from the habit of clenching or grinding the teeth generate abnormal loads on the masticatory system, affecting the alveolar bone, supporting periodontium and temporomandibular joint (TMJ), which can lead to temporomandibular disorders, muscle pain, tooth wear and tooth $\operatorname{loss}^{3-5}$.

The prevalence of bruxism in children varies widely due to the difficulty in obtaining information, differences in assessment criteria and differences in the population studied ${ }^{6-8}$. A systematic review of the literature reports a broad prevalence range of 5.9 to $49.6 \%$. Despite the growing number of studies aimed at attempted to clarify the etiology of this condition, divergent opinions are found, but most studies report a multifactor origin involving peripheral (morphological) and central (pathyphysiological and psychological) factors ${ }^{3,10-12}$.

While considerable attention has been given to the prevalence, etiology and treatment of bruxism, only two studies were found evaluating the knowledge of parents and caregivers on this subject. Both were conducted with caregivers of Brazilian children and had samples composed of 221 and 134 parents, respectively ${ }^{13,14}$. In the study by Serra-Negra et al. ${ }^{13}, 95 \%$ of the interviewees reported having knowledge on the subject and $95.5 \%$ of these individuals described the parafunctional habit correctly. Approximately $53.2 \%$ of the interviewees had interest in having further explanations about the subject. In the study by Tavares Silva et al. ${ }^{14}$, only $38.1 \%$ of the parents/caregivers correctly defined bruxism. The majority of interviewees $(73.9 \%)$ were unaware of the causes of bruxism and $13.4 \%$ of those who answered this question related the condition to emotional factors.

It is important to measure knowledge on bruxism among caregivers, since these individuals frequently enter their children's rooms at night and are therefore the closest source of information on the habits of children. An evaluation of this knowledge would enable the establishment of actions that could provide the necessary information so that parents/caregivers could take the initiative to seek assistance. Therefore, the aim of the present study was to evaluate knowledge on bruxism among caregivers of children treated in a pediatric dentistry clinic.

\section{MATERIAL AND METHODS}

This study received approval from the Human Research Ethics Committee of the Ceuma University (certificate number: 1.165.214/2015). All participants signed a statement of informed consent.
A cross-sectional study was conducted at the pediatric dentistry clinic of the Ceuma University in the city of São Luís (northeastern Brazil) between August and October 2015. For inclusion in the study, the volunteers should be parents or caregivers of the children, be literate in Portuguese and have sufficient cognitive and mental capacity to fill out the questionnaire and the children needed to be between three and twelve years old.

The sample size was calculated considering a $50 \%$ frequency of correct knowledge on bruxism among the caregivers, a $5 \%$ acceptable error rate and $95 \%$ confidence interval, leading to an initial " $\mathrm{n}$ " of 384 . Considering the adjustment for finite populations (based on the registry of 216 new pediatric patients at the dental clinic in the previous eight months), the final " $\mathrm{n}$ " was determined to be 139 .

The data were collected using a questionnaire designed by Serra-Negra et al. ${ }^{13}$ based on the criteria of the American Association of Sleep Medicine. The questionnaire was first tested in a pilot study with 20 volunteers who were not included in the main study. The parents/caregivers filled out the questionnaire without the assistance of an accompanier or the researcher in a reserved room at the dental clinic while the child was undergoing dental care. No information that could alter the volunteers' answers was offered.

The questionnaire was composed of 18 items. Eleven items addressed the following objective information: degree of kindship of the interviewer with the child; child's sex; child's sleep characteristics (adequate or not); type of child' sleep (agitated or not); whether the child sleeps alone; whether the respondent know what bruxism is; whether the respondent has bruxism; whether the child has bruxism; whether the respondent ever sought help for bruxism; whether bruxism can affect the people's lives; and whether the respondents are interested in more information on the subject. Additionally, seven openended questions addressed the age of the respondent and the child, hours of sleep of the child, concept of bruxism, cause of bruxism, whether the respondent sought help, the type of help and whether bruxism affects the people's lives and what negative effects bruxism can have ${ }^{13}$.

The variable "what is bruxism" was categorized as correct concept, incorrect concept or does not apply. The act of clenching or grinding the teeth was considered the "correct concept" and all other answers were considered "incorrect concept". The number of hours the child sleeps was dichotomized as $\leq$ eight hours and $>$ eight hours. Child's age was dichotomized as $\leq$ seven years and $>$ seven years. The responses to the variables "cause of bruxism" were categorized as emotional factor (all answers related to anxiety, nervousness, fear, stress, depression and fatigue), dental problems (answers related to local factors, such as tooth wear) and medical problems (answers related to neurological disorders).

The Statistical Package for the Social Sciences (SPSS for Windows, version 21.0; SPSS Inc., Chicago, IL, USA) was used for the data analysis, which involved descriptive and inferential (Pearson's $\chi^{2}$ test and Fisher's exact test) statistics, at a significance level of $5 \%$. 


\section{RESULTS}

The response rate for the survey was $74.1 \%$. Most participants were mothers $(63.1 \%)$. The prevalence of bruxism was $25.2 \%$ among the children and $16.5 \%$ among the caregivers (Table 1). Mean age was 34.17 ( \pm 9.55 ) years among the caregivers and $7.36( \pm 2.34)$ years among the children.

Sixty-seven percent of caregivers said they know what bruxism is. Of these $67 \%, 52.4 \%$ defined the parafunctional habit correctly. Regarding the cause of bruxism, $74.8 \%$ were unable to say and $16.5 \%$ associated the habit to an emotional factor. Among the caregivers of the 26 children with bruxism, only $2.9 \%$ had sought some type of help. Among the $71.8 \%$ who said that bruxism affects people's lives, $31.1 \%$ said that it causes dental problems (Table 2).

Child's sex, child's sleep and the search for help were significantly associated with bruxism $(p=0.034,0.013$ and $<0.001$, respectively) (Table 3).

\section{DISCUSSION}

The main outcome measured in the present study was the knowledge caregivers have regarding bruxism. Of those who said they knew what bruxism is, $52.4 \%$ defined it correctly. Mothers were the predominant caregivers who participated in the study $(63.1 \%)$, which demonstrates that they are primarily responsible for the health of their children. Seventeen caregivers $(16.5 \%)$ and 26 children (25.2\%) had bruxism. Bruxism was significantly associated with sex and seeking help. Bruxism was more prevalent in the boys. Among the children with this parafunctional habit, help was sought for $11.5 \%$.

Table 1. Aspects related to caregivers and children.

\begin{tabular}{lc}
\hline & $\mathbf{n}(\mathbf{\%})$ \\
\hline Child's caregiver & $65(63.1)$ \\
\hline Mother & $18(17.5)$ \\
\hline Father & $8(7.8)$ \\
\hline Grandparent & $12(11.7)$ \\
\hline Other & $17(16.5)$ \\
\hline Caregiver has bruxism & $86(83.5)$ \\
\hline Yes & $33(32)$ \\
\hline No & $31(30.1)$ \\
\hline Caregiver's age & $39(37.9)$ \\
\hline $18-29$ years & \\
\hline $30-35$ years & $58(56.3)$ \\
\hline $36-70$ years & $45(43.7)$ \\
\hline Child's age & \\
\hline$\leq 7$ years & $58(56.3)$ \\
\hline$>7$ years & $45(43.7)$ \\
\hline Child's sex & $26(25.2)$ \\
\hline Female & $77(74.8)$ \\
\hline Male &
\end{tabular}

Table 2. Questions about bruxism answered by caregivers.

\begin{tabular}{|c|c|}
\hline & n (\%) \\
\hline \multicolumn{2}{|l|}{ Do you know what bruxism is? } \\
\hline Yes & $69(67.0)$ \\
\hline No & $34(33.0)$ \\
\hline \multicolumn{2}{|l|}{ Concept of bruxism } \\
\hline Correct & $54(52.4)$ \\
\hline Incorrect & $15(14.6)$ \\
\hline Not applicable & $34(33)$ \\
\hline \multicolumn{2}{|l|}{ Cause of bruxism* } \\
\hline Emotional factor & $17(16.5)$ \\
\hline Mystical influence & $1(1.0)$ \\
\hline Dental problems & $3(2.9)$ \\
\hline Medical problems & $1(1.0)$ \\
\hline Do not know & $77(74.8)$ \\
\hline \multicolumn{2}{|l|}{ Does bruxism affect health? } \\
\hline Yes & $74(71.8)$ \\
\hline No & $28(27.2)$ \\
\hline Do not know & $1(1.0)$ \\
\hline \multicolumn{2}{|l|}{ Problems caused by bruxism } \\
\hline Dental & $32(31.1)$ \\
\hline Facial pain, headache and TMJ pain & $7(6.8)$ \\
\hline Emotional & $4(3.9)$ \\
\hline Psychological & $2(1.9)$ \\
\hline Do not know & $29(28.2)$ \\
\hline Not applicable & $29(28.2)$ \\
\hline \multicolumn{2}{|l|}{ Did you seek help? } \\
\hline Yes & $3(2.9)$ \\
\hline No & $23(22.3)$ \\
\hline Not applicable ** & $77(74.8)$ \\
\hline \multicolumn{2}{|l|}{ Type of help } \\
\hline Did not seek & $23(22.3)$ \\
\hline Research the internet and search the sought pediatrician & $1(1.0)$ \\
\hline Questions asked to dentist & $2(1.9)$ \\
\hline Not applicable $* *$ & $77(74.8)$ \\
\hline \multicolumn{2}{|l|}{ Do you want further information? } \\
\hline Yes & $99(96.1)$ \\
\hline No & $4(3.9)$ \\
\hline
\end{tabular}

** children without bruxism

The percentage of those who said they know what bruxism $(67 \%)$ is lower than the figure reported in the study by Serra-Negra et al. ${ }^{13}$, in which $95 \%$ of the interviewees reported knowing what bruxism is. In this study, $95.5 \%$ of the participants defined the parafunctional habit correctly. In contrast, only $52.4 \%$ of the participants in the present investigation and $38.1 \%$ of those in the study conducted by Tavares Silva et al. ${ }^{14}$ correctly defined the concept.

The present results may be directly related to the more unfavorable social indicators of the northeastern region of Brazil, which is where the present study was conducted, in comparison to the southeastern region of the country, which is where the study by Serra-Negra et al. ${ }^{13}$ was conducted. The lack of access to healthcare services may also exert an influence 
Table 3. Association between bruxism in child and independent variables related to child and caregiver.

\begin{tabular}{|c|c|c|c|}
\hline \multirow[b]{2}{*}{ Variables } & \multicolumn{2}{|c|}{ Bruxism in Child } & \multirow[b]{2}{*}{$p$} \\
\hline & $\begin{array}{l}\text { Present n } \\
\quad(\%)\end{array}$ & $\begin{array}{c}\text { Absent } \\
\mathrm{n}(\%)\end{array}$ & \\
\hline \multicolumn{4}{|l|}{ Related To Child } \\
\hline \multicolumn{4}{|l|}{ Sex } \\
\hline Female & $10(38.5)$ & $48(62.3)$ & 0.034 \\
\hline Male & $16(61.5)$ & $29(37.7)$ & \\
\hline \multicolumn{4}{|l|}{ Age } \\
\hline$\leq 7$ years & $17(65.4)$ & $41(53.2)$ & 0.281 \\
\hline$>7$ years & $9(34.6)$ & $36(46.8)$ & \\
\hline \multicolumn{4}{|l|}{ Hours of sleep $\mathbb{S}$} \\
\hline$\leq 8$ & $10(38.5)$ & $38(50.7)$ & 0.283 \\
\hline$>8$ & $16(61.5)$ & $37(49.3)$ & \\
\hline \multicolumn{4}{|c|}{ Does your child sleep well? } \\
\hline Yes & $15(57.7)$ & $63(81.8)$ & 0.013 \\
\hline No & $11(42.3)$ & $14(18.2)$ & \\
\hline \multicolumn{4}{|l|}{ Kind of sleep } \\
\hline Agitated ${ }^{* *}$ & $21(80.8)$ & $47(61.0)$ & 0.066 \\
\hline Normal & $5(19.2)$ & $30(39.0)$ & \\
\hline \multicolumn{4}{|l|}{ Sleep alone } \\
\hline Yes & $5(19.2)$ & $27(35.1)$ & 0.131 \\
\hline No & $21(80.8)$ & $50(64.9)$ & \\
\hline \multicolumn{4}{|c|}{ Related to or Answered by Caregiver } \\
\hline \multicolumn{4}{|c|}{ Caregiver has bruxism } \\
\hline Yes & $6(23.1)$ & $11(14.3)$ & $0.361 *$ \\
\hline No & $20(76.9)$ & $66(85.7)$ & \\
\hline \multicolumn{4}{|c|}{ Does bruxism affect health? } \\
\hline Yes & $22(84.6)$ & $52(67.5)$ & $0.090^{*}$ \\
\hline No & $4(15.4)$ & $24(31.2)$ & \\
\hline \multicolumn{4}{|l|}{ Did you seek help? } \\
\hline Yes & $3(11.5)$ & $0(0)$ & $<0.001^{*}$ \\
\hline No & $23(88.5)$ & $0(0)$ & \\
\hline Not applicable $* * *$ & $0(0)$ & $77(100)$ & \\
\hline \multicolumn{4}{|c|}{$\begin{array}{l}\text { Do you want further information on } \\
\text { bruxism? }\end{array}$} \\
\hline Yes & $26(100.0)$ & $73(94.8)$ & $0.570^{*}$ \\
\hline No & $0(0.0)$ & $4(5.2)$ & \\
\hline
\end{tabular}

on health information. Early access to dental services enables the demystification of a set of mistaken concepts regarding health. Incorrect concepts regarding bruxism in the present study were related to witchcraft, diseases, compulsions/habits, hallucination, agitated sleep, nervousness and bad thoughts.

The frequency of bruxism among the children $(25.2 \%)$ was lower than the rate described in other studies that used the same diagnostic criteria (caregivers' reports). A study conducted at the Boston Children's Hospital (USA) with 854 parents/ caregivers of children found a $38 \%$ frequency of bruxism in the children ${ }^{6}$. A similar result was found in a study conducted with 652 Brazilian children at the teaching clinic of the Federal
University of Minas Gerais in the city of Belo Horizonte $(35.3 \%)^{15}$. The difference in prevalence rates may be due to the different sample sizes, age groups evaluated and methods for diagnosing the condition ${ }^{6-8,16}$.

Among the 17 caregivers with bruxism, six also had children with the parafunctional habit. Moreover, among the children with bruxism $(n=26)$, only the caregivers of three sought help, two of whom consulted a dentist. The low frequency of seeking some type of help is in agreement with data described in a study conducted with the parents of children six to nine years of age at public and private schools in the city of Poços de Caldas (southeastern Brazil), in which only $4.2 \%$ of the parents sought care for the sleep disorder of their children ${ }^{17}$. In contrast, the vast majority of interviewees $(97.6 \%)$ in a study conducted in the city of Belo Horizonte (southeastern Brazil) sought help to clarify the condition; the most sought professionals were physicians $(54.4 \%)$, followed by mystics $(26.5 \%)$ and dentists $(19.1 \%)^{13}$. In a study conducted in the city of Rio de Janeiro (southeastern Brazil), 33.6\% of the caregivers of children with bruxism reported that they did not seek help and $54.5 \%$ of the participants did not answer the question. In the present investigation, the professional most consulted was a dentist $(10.4 \%)$, followed by a physician and psychologist $(0.7 \%$ of the participants for each of these two specialists $)^{14}$.

It is extremely important for parents/caregivers to know what bruxism is, since only then will they be able to detect the habit and seek the help with any health professional. When this parafunctional habit is unknown, individuals may make mistaken associations and seek treatments unrelated to parafunction. Moreover, a lack of information prevents parents/caregivers from giving due importance to the condition, which can lead to irreversible consequences in adulthood.

With regard to the etiology, the majority of interviewees $(74.8 \%)$ were unable to say what led to bruxism. Seventeen interviewees (16.5\%) associated bruxism with emotional factors, which is in agreement with findings described in similar studies $^{13,14}$, although the percentage of interviewees who considered emotional aspects to be the causal factor of bruxism was considerably higher $(63.8 \%)$ in the study by Serra-Negra et al. ${ }^{13}$. Regarding the mystical aspects, $20.4 \%$ of the interviewees in the study Serra-Negra et al. ${ }^{13}$ believed that witchcraft was the probable cause of bruxism, whereas only one caregiver $(1 \%)$ in the present study attributed the parafunctional habit to this cause. This is closer to the finding described by Tavares Silva et al. ${ }^{14}$, who found that $3.7 \%$ of the participants cited mystical/ religious influences as the cause of bruxism.

The type of sleep was not associated with bruxism, regardless of the finding of Serra-Negra et al..$^{13}$, who found a significant association between agitated sleep and bruxism $(p<0.001)$. In a study conducted in the city of São Paulo (southeastern Brazil) involving 937 children, from two to six years of age, questionnaires were applied to parents/caregivers and clinical examination was performed on the children. Children with agitated sleep were found to be more susceptible to developing bruxism, presenting a 2.4-fold greater chance of having the 
parafunctional habit ${ }^{18}$. In a study conducted with 450 children at the pediatric dentistry clinic of the University of Santo Amaro, bruxism was associated with both agitated sleep and anxiety ${ }^{19}$. According to the International Classification of Sleep Disorders $(\text { ICSD-3 })^{20}$, bruxism is considered a sleep-related movement disorder associated with arousals during the night.

In contrast to the present findings, a study conducted with Brazilian caregivers and children found that bruxism in the mother or father was significantly associated with bruxism in the child, as among the 88 fathers with this condition, 66 children also had bruxism and among the 104 mothers with the habit, 86 children had bruxism ${ }^{13}$, indicating that this parafunctional habit may be linked to hereditary factors or family problems. Indeed, one study addressing genetic predisposition confirmed that parents who had bruxism as a child may have children with the condition ${ }^{21}$.

The present study involved a convenience sample, which impedes the generalization of the findings to similar populations. Thus, community-based studies with representative samples should be conducted. The measurement of this knowledge will enable the establishment of public policies that can provide greater clarification of this habit for parents/caregivers. This will allow caregivers to look for a diagnostic confirmation of bruxism in their children and establish early treatment, which would lead to a reduction in the number of problems stemming from this parafunctional habit.

\section{CONCLUSION}

Based on the findings of the present study, knowledge among caregivers about bruxism is insufficient, especially with regard to the etiology of this parafunctional habit. The lack of knowledge impedes caregivers from seeking help, which contributes to the worsening the bruxism consequences in adulthood.

\section{REFERENCES}

1. Pietkiewicz M. La bruxomanie: memoires originux. Rev Estomatol. 1907;14:107-16.

2. Lobbezoo F, Ahlberg J, Raphael KG, Wetselaar P, Glaros AG, Kato T, et al. International consensus on the assessment of bruxism: Report of a work in progress. J Oral Rehabil. 2018;45(11):837-44.
3. Carra MC, Huynh N, Morton P, Rompré PH, Papadakis A, Remise C, et al. Prevalence and risk factors of sleep bruxism and wake-time tooth clenching in a 7- to 17-yr-old population. Eur J Oral Sci. 2011;119(5):386-94.

4. Murray GM, Peck CC. Orofacial pain and jaw muscle activity: a new model. J Orofac Pain. 2007;21(4):263-78.

5. Carrara SV, Conti PCR, Barbosa JS. Statement of the 1st Consensus on Temporomandibular Disorders and Orofacial Pain. Dental Press J Orthod. 2010;15(3):114-20.

6. Cheifetz AT, Osganian SK, Allred EM, Needleman HL. Prevalence of bruxism and associated correlates in children as reported by parents. J Dent Child (Chic). 2005;72(2):67-73.

7. Fonseca CM, dos Santos MB, Consani RL, dos Santos JF, Marchini L. Incidence of sleep bruxism among children in Itanhandu, Brazil. Sleep Breath. 2011;15(2):215-20.

8. Junqueira TH, Nahás-Scocate AC, Valle-Corotti KM, Conti AC, Trevisan S. Association of infantile bruxism and the terminal relationships of the primary second molars. Braz Oral Res. 2013;27(1):42-7.

9. Machado E, Dal-Fabbro C, Cunali PA, Kaizer OB. Prevalence of sleep bruxism in children: a systematic review. Dental Press J Orthod. 2014;19(6):54-61.

10. Serra-Negra JM, Ramos-Jorge ML, Flores-Mendoza CE, Paiva SM, Pordeus IA. Influence of psychosocial factors on the development of sleep bruxism among children. Int J Paediatr Dent. 2009;19(5):309-17.

11. Lobbezzo F, Naeije M. Bruxism is mainly regulated centrally, not peripherally. J Oral Rehabil. 2001;28(12):1085-91.

12. Ferreira-Bacci Ado V, Cardoso CL, Díaz-Serrano KV. Behavioral problems and emotional stress in children with bruxism. Braz Dent J. 2012;23(3):246-51.

13. Serra-Negra JM, Tirsa-Costa D, Guimarães FH, Paiva SM, Pordeus IA Evaluation of parents/guardian knowledge about the bruxism of their children: Family knowledge of bruxism. J Indian Soc Pedod Prev Dent. 2013;31(3):153-8.

14. Tavares Silva C, Calabrio IR, Serra-Negra JM, Fonseca-Gonçalves A, Maia LC. Knowledge of parents/guardians about nocturnal bruxism in children and adolescents. Cranio. 2017;35(4):223-7.

15. Serra-Negra JM, Paiva SM, Seabra AP, Dorella C, Lemos BF, Pordeus IA Prevalence of sleep bruxism in a group of Brazilian schoolchildren. Eur Arch Paediatr Dent. 2010;11(4):192-5.

16. Restrepo CC, Alvarez E, Jaramillo C, Vélez C, Valencia I. Effects of psychological techniques on bruxism in children with primary teeth. J Oral Rehabil. 2001;28(4):354-60.

17. Valle LELR, Valle ELR, Reimão R. Sleep and Learning. Rev Psicopedag. 2009;26(80):286-90.

18. Nahás-Scocote ACR, Trevison S, Junqueira TH, Fuziy A. Association between infant bruxismo and occlusal characteristics, sounds and headache. Rev Assoc Paul Cir Dent. 2012;66(1):18-22.

19. Laucis-Pinto S, Diegues MB, Ferreira SLM, Simonato CASS. Pediatric bruxism and relationship with oral habits. Rev Paul Odontol. 2000;22(5):10-8.

20. American Academy of Sleep Medicine. International Classification of Sleep Disorders. 3nd ed. Westchester: American Academy of Sleep Medicine; 2014.

21. Abe K, Shimakawa M. Genetic and developmental aspects of sleep talking and teeth-grinding. Acta Paedopsychiatr. 1966;33(11):339-44. 